\title{
UNIVERSITYOF
}

FORWARD

THINKING

WESTMINSTER用

WestminsterResearch

http://www.westminster.ac.uk/westminsterresearch

Modelling the Home Health Care Nurse Scheduling Problem for

Patients with Long-Term Conditions in the UK

He, F., Chaussalet, T.J. and Qu, R.

A paper presented at the 33rd International ECMS Conference on modelling and Simulation. Universita degli Studi della Campania, Caserta, Area of Napoli, Italy 11 - 14 Jun 2019.

The WestminsterResearch online digital archive at the University of Westminster aims to make the research output of the University available to a wider audience. Copyright and Moral Rights remain with the authors and/or copyright owners.

Whilst further distribution of specific materials from within this archive is forbidden, you may freely distribute the URL of WestminsterResearch: ((http://westminsterresearch.wmin.ac.uk/)).

In case of abuse or copyright appearing without permission e-mail repository@westminster.ac.uk 


\section{MODELLING THE HOME HEALTH CARE NURSE SCHEDULING PROBLEM FOR PATIENTS WITH LONG-TERM CONDITIONS IN THE UK}

\author{
Fang He \\ School of Computer Science \\ and Engineering \\ College of Design, Creative \\ and Digital Industries \\ University of Westminster \\ 115 New Cavendish Street \\ London, W1W 6UW,UK \\ Email: hef@,westminster.ac.uk
}

\author{
Thierry Chaussalet \\ School of Computer Science \\ and Engineering \\ College of Design, Creative \\ and Digital Industries \\ University of Westminster \\ 115 New Cavendish Street \\ London, W1W 6UW, UK \\ Email: chausst@westminster.ac.uk
}

\author{
Rong Qu \\ The Automated Scheduling, \\ Optimisation and Planning (ASAP) \\ Group \\ School of Computer Science \\ The University of Nottingham \\ Nottingham, NG8 1BB, UK \\ Email: Rong.Qu@nottingham.ac.uk
}

\section{KEYWORDS}

Home Health Care, Nurse Scheduling Problem Modelling, Behavioural Operational Research

\begin{abstract}
In this work, using a Behavioural Operational Research (BOR) perspective, we develop a model for the Home Health Care Nurse Scheduling Problem (HHCNSP) with application to renal patients taking Peritoneal Dialysis (PD) at their own homes as treatment for their Chronic Kidney Disease (CKD) in the UK. The modelling framework presented in this paper can be extended to much wider spectra of scheduling problems concerning patients with different long-term conditions in future work.
\end{abstract}

\section{INTRODUCTION}

Medical advances have turned many life-threatening conditions, such as kidney failure, into long-term conditions. More and more people survive acute episodes of illness and live many years with their conditions (Ham et al. 2012). The rise of the prevalence of long-term conditions has presented many challenges to the current health and social care systems. People diagnosed with long-term conditions are the most intensive users of health and social care services because their needs are usually more complex than those with acute diseases (Ham et al. 2012).

During the past decade, research has been focused on integrated care models as a solution to build more effective and efficient healthcare systems that can better meet the needs of patients and the populations (Chouvarda et al. 2015). This is especially the case for the patients with chronic conditions, such as chronic kidney disease (CKD), cancer, diabetes etc., where patients typically require a relatively broad mix of services across sectors over time (Ham et al. 2012). For example, a patient with CKD requires care provided by a wide range of healthcare professionals (e.g. nephrologist, surgeons, hospital nurses, community nurses, social workers, etc.) in different care settings (specialised/comprehensive kidney disease centres, teaching and community hospitals, dialysis centres, patients' own homes etc.) throughout their renal disease treatment journey. High quality care requires a seamless service from the beginning to the end; therefore it is essential to use the workforce resources in an efficient way. In other words, we need allocate the right staff with the necessary skills in the right place at the right time in this long journey for CKD patients.

Our general research topic concerns the workforce management for the patients with long-term conditions. In this preliminary work, we will study the Home Health Care Nurse Scheduling Problem (HHCNSP) for CKD patients taking Peritoneal Dialysis (PD) treatment at their own homes. For the majority of patients, CKD is a life long condition. Treatment, care, and support should be compatible with the patients' overall lifestyle and maximize the rehabilitation into society. This motivates us to take the patients' perspectives into account in the HHCNSP, and we aim to have better understanding of how the patients' perspectives may impact on the workforce scheduling in the integrated healthcare delivery.

\section{LITERATURE REVIEW}

\section{Modelling with patients' perspectives}

In the literature of workforce management problem, to our knowledge, there are very sparse works that take human's behaviour factors, or patients' perspectives into account in the modelling process. However, continuity of care, a related topic, can be interpreted to consider patients' perspectives in the modelling process.

"Continuity of care" refers to that medical and paramedical care are delivered by means of a sequence of coordinated and uninterrupted practices consistent with patients' needs, if possible by the same caregiver in each practice (Shortell 1976). With the continuity of care, the patients normally receive care from the same caregiver and do not have to continuously develop new 
relationships with new caregivers. On the other hand, the care operators can build detailed profiles on the patients during this long-term care, thus any potential loss of information among caregivers is circumvented (Lanzarone and Matta 2014). Despite the importance of this topic, continue of care is only marginally addressed in the literature (Borsani et al. 2006; Hertz and Lahrichi 2009; Lanzarone et al. 2012). More work is required to add patients' behavioural factors into modelling in this case.

\section{Behavioural Operational Research approach to healthcare delivery}

OR research has been widely applied to healthcare problems, which can potentially lead to more effective and efficient healthcare. However, a significant proportion of the research findings failed in practice, this can be down to research did not take human factor into consideration when the researcher modelling the healthcare process. The lacking of the consideration of human factors in the modelling, among many of other causes, may have hampered the effective solution transfer from academia to clinics.

Applying new insights from patients' behaviours to their care plans can lead to better healthcare outcomes at a lower cost. A previous study (Hallsworth, et al. 2016) gave an overview of these insights and showed how they can be applied in practice, mainly in health policy making. In the report it stated that healthcare systems consist of many different relationships. As well as the direct patient-practitioner relationships, there are patient-family/community relationships, practitionerpractitioner relationships, provider-commissioner relationships, and so on. Understanding what drives and influences the way these participants interact could result in better healthcare outcomes for less money.

Pessôa et al. (2015) presented the practical applications of an integrated use of soft and hard methodologies applied in a case study of a surgical centre, where the low volume of surgeries taken place was the major issue. Cognitive maps were used to elicit the perspectives of the health professionals, which supported simulations and guided the execution of the model. It was found that many factors, including human resources, patients, room schedules, material and structural constraints, affected the number of surgeries to be performed. This multi-methodology approach demonstrated, in addition to traditional hard OR methods, soft OR methodologies, such as Behavioural OR, can collaborate work together and provide solutions to real-world problems.

\section{Home Heath Care Problem}

Home health care (HHC) has been widely studied due to its significance in the healthcare for the patients with long-term conditions. The HHC consists of delivering medical, paramedical and social services to patients at their domicile rather than in a hospital. On the one hand the HHC leads to a significant improvement in the quality of life for patients, as they continue to live in a familiar environment. On the other hand this approach makes considerable cost savings in the health care system, as the hospitalization costs are circumvented. The HHC is a fast growing healthcare approach particularly in western countries, because these societies are under unprecedented pressure from aging population, increase in chronic pathologies and soaring healthcare cost. In the meantime, the fast introduction of innovative technologies also accelerates the practice of the HHC in these societies.

The HHC services involve diverse professional figures. Patients are usually assisted by nurses and, depending on the cases, may also require the supports from other professionals, such as physiotherapists, physicians, and psychologists. In some cases, they may require specific facilities to be brought and managed at home. Hence, many resources, including nurses and other categories of operators, support staff and material resources, are involved in the delivering of the HHC services.

The HHC involves the management of several resources and must take into account many requirements and constraints. Nurse rostering in hospitals (see Burke et al. 2004; Cheang et al. 2003) is one component of the HHC as the healthcare inevitably deals with nurse management. However, in HHC services there are some unique nurse rostering features that are not usually addressed in conventional nurse rostering problems. These features include the continuity of care (Haggerty et al. 2003) and the burnout risk (Borsani et al. 2006), which make the HHC nurse management distinctive from the conventional approaches. In particular, the main issues to be considered are the partitioning of a territory into districts, the dimensioning of human resources, the assignment of the visits to operators (or the patients to operators in the case of continuity of care), the scheduling of nurses' duties and the routing optimization (Carello, and Lanzarone 2014).

Previous studies on the HHC problem can be mainly divided into two groups: one group dealt with the daily schedule of parents visits and the routing of nurses, and the other group dealt with the staff planning and management from a mid/ long-term perspective. In the latter one, the districting problem involved the grouping of patients and nurses according to the geography and skill compatibility, usually aiming at balancing the workload among different groups (Blais et al. 2003; Lahrichi et al. 2006; Carello, and Lanzarone, 2014).

\section{PROBLEM DESCRIPTION}

In Fig. 1, we illustrate a typical care pathway for the patients with CKD undertaken the PD treatment in a major renal unit in the UK. Among all the renal patients in the unit, only those medically eligible for the PD could enter the PD treatment programme. The care for 
these patients usually include 1) Biochemical and nutritional monitoring and diagnosis. The hospital nurses in the renal unit perform this. 2) Non-surgical treatments and assistances. The named renal community dialysis nurses perform this. 3) Psychological and social aspects of treatment and care. Social care workers performed this.

In the pathway, a PD catheter insertion surgery is performed, usually followed by a two-week healing period. Following the discharge to the community, the patients receive a short period of PD training at home or in hospital. Community dialysis nurses pay frequent home visits to the patients, and the patients need to attend several outpatient clinic check-ups in the hospital. After the patients enter a "steady state" in their PD treatments, the patients will conduct the PD independently at home. The frequency of the follow-up HHC visits delivered by the community dialysis nurses depends a great deal on the patients' confidence and general conditions. Most of the stable patients only need attend the renal unit for clinical review ever 3-4 months. For patients with additional needs, their HHC visits are conducted by a range of specialized PD nurses, community nurses and social care workers. The HHC visit consists of a diverse set of tasks, including the collection of dialysate and urine samples, blood tests, patients' regular check-ups, etc.

The BRS gives guidelines on the care pathways and the workforce planning for renal patient care teams, mainly based on patients' medical conditions. Here, we summarise some key guidelines closely related to the care pathway:

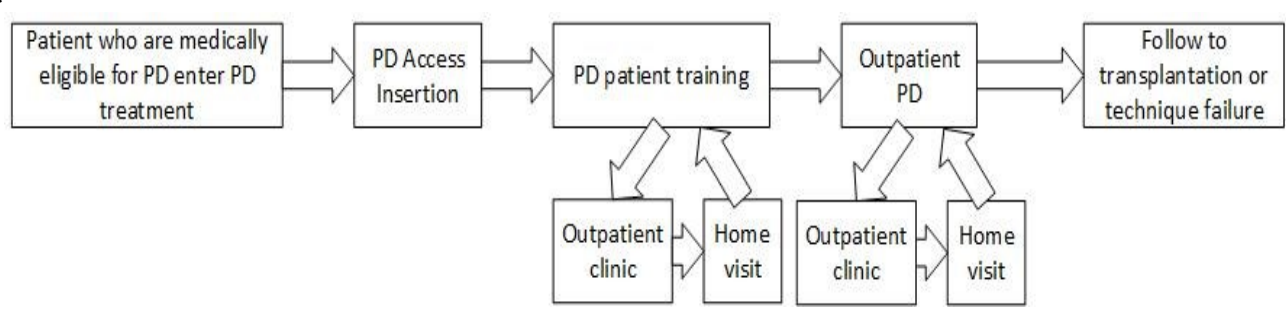

Fig. 1 The illustration of the care pathway for the patients in the PD treatment in a major renal unit in the UK.

\section{MODELLING}

\section{Patient profile modelling}

Patients' perspectives consist of patients' health condition, as well as their behavioural factors. Primarily the patient's care plan is conducted based on their health conditions, e.g. biochemical and nutritional markers, etc. The care pathway given by British Renal Society (BRS) needs to be strictly adhered to. That is, the medical conditions of patients should be the principle factors to consider when designing the care plan for the patients. At the same time, the BRS indicates that the care plan needs to be able to be adjusted and tailored to patients' individual needs, life styles and personal preferences. It is essential to have the patients stick on a. All patients should, where possible, be adequately prepared for renal replacement therapy and this should include receiving information and education about PD treatment.

b. Where possible, timing of PD catheter insertion should be planned to accommodate patient convenience, commencement of training between 10 days and 6 weeks to enable correction of early catheter-related problems without the need for temporary haemo dialysis.

c. Dialysis centres should have a dedicated team approach to catheter insertion.

d. Both residual urine and peritoneal dialysis components of small solute clearance should be measured at least six monthly or more frequently if clinically indicated.

e. Peritoneal membrane function should be monitored regularly (6 weeks after commencing treatment and at least annually or when clinically indicated). Daily urine and peritoneal ultrafiltration volumes, with appropriate correction for overfill, should be monitored at least six-monthly.

f. Patients should undergo regular revision of their technique and receive intensified training if this is below standard.

Based on these guidelines and our consultancy with the PD team in the renal unit in this study, we will model these factors into our model. 
Some of patients' individual needs, i.e. life styles and personal preferences may be easy to identify and describe, thus they are relatively simple to be modelled in the profile. For example, in the category of life styles the patients who have full time jobs are not available at normal working hours, therefore any home visits should be scheduled to be delivered at out of hours as much as possible. However, some of patients' individual needs are more intangible. A reliable and tangible measure is needed to describe patients' individual needs. We propose that the patients' health literacy can be a valuable measurement for individual needs.

The Institute of Medicine defines the health literacy as "the degree to which individuals have the capacity to obtain, process, and understand basic health information and services needed to make informed health decisions" (Taylor et al. 2017). The health literacy is a complex issue including diverse communication skills of individuals beyond simply being able to read. It also involves oral understanding (speaking and listening skills), numeracy, and cultural and conceptual knowledge. The prevalence of limited health literacy is higher amongst the elderly, minorities and those with lower socioeconomic status including income and education (Taylor et al. 2017).

Health literacy is particularly important in the large and growing number of patients with $\mathrm{CKD}$ due to the complexity of the disease, which requires a high level of patient involvement and self-management skills. The patients with kidney diseases must follow appropriate dietary restrictions, adhere to complex medication regimens, make decisions about dialysis, and keep up with multiple appointments in the health care system. There is increasing evidence that health literacy plays an important role in the care of patients with kidney disease.

One key massage we can take from these cohort researches is that there is a significant association between the patient health literacy and dialysis initiation. This is consistent with the comments from the head nurse in the PD team we interviewed in the renal unit. Patients' health literacy decides the time and length of dialysis initiation, and also the length and frequency of home visits. Thus we propose to use health literacy as a measurement to profile patients. Consequently a mid-term care plan for each patient will be developed. The plan consists of the initial time and length of dialysis training, and the length and frequency of home visits etc., which are tailored to individual patients' needs according to different patient profiles. In Table 3, we illustrate the structure of a mid-term care plan for a patient.

Based on this plan, a list of tasks for each patient is prepared (Table 4). In this list, each visit is assigned to specific time windows. Some of the task's time windows can be tight while others are more flexible, depending on the nature of the tasks and the conditions of the patients. It should be mentioned here that the complexity of the model is embedded in this task list. It links tasks, patients, nurses' skills and time slots together.

Table 2. Health literacy measures used in some studies given in a review(Taylor et al. 2017)

\begin{tabular}{|c|c|c|c|c|}
\hline $\begin{array}{l}\text { Health literacy } \\
\text { measure }\end{array}$ & $\begin{array}{l}\text { Number of } \\
\text { studies using } \\
\text { measure (\%) }\end{array}$ & Form & $\begin{array}{l}\text { Approximate } \\
\text { time taken }\end{array}$ & Health literacy categorization \\
\hline $\begin{array}{l}\text { Short test of func- } \\
\text { tional health literacy } \\
\text { in adults (STOFHLA) }\end{array}$ & $10(34)$ & $\begin{array}{l}36 \text { reading comprehension items-select from four } \\
\text { choices to replace missing words in text (modified } \\
\text { Cloze procedure) }\end{array}$ & $12 \mathrm{~min}$ & $\begin{array}{l}\text { 0-22: limited } \\
\text { 23-36: adequate }\end{array}$ \\
\hline $\begin{array}{l}\text { Rapid estimate of } \\
\text { adult health literacy } \\
\text { in medicine } \\
\text { (REALM) }\end{array}$ & $9(31)$ & $\begin{array}{l}125 \text { health-related words ( } 66 \text { in more commonly } \\
\text { used form) tested for pronunciation accuracy }\end{array}$ & $3 \mathrm{~min}$ & $\begin{array}{l}0-44: \text { inadequate } \\
\text { 45-60: marginal } \\
\text { 61-66: adequate } \\
\text { (limited = inadequate }+ \text { marginal) }\end{array}$ \\
\hline REALM-T & $2(7)$ & $\begin{array}{l}\text { Transplant-specific version of REALM. } 69 \text { kidney } \\
\text { transplant-related terms tested for pronunciation } \\
\text { accuracy }\end{array}$ & $3 \mathrm{~min}$ & Not clearly defined \\
\hline REALM-SF & $3(10)$ & $\begin{array}{l}\text { Short Form of REALM. Seven health-related words } \\
\text { tested for pronunciation accuracy }\end{array}$ & $2-3 \min$ & $\begin{array}{l}0-3: \text { inadequate } \\
\text { 4-6: marginal } \\
\text { 7: adequate }\end{array}$ \\
\hline $\begin{array}{l}\text { Brief health literacy } \\
\text { screen (BHLS) }\end{array}$ & $3(10)$ & $\begin{array}{l}\text { Three questions: } \\
\text { How confident are you filling out forms by yourself? } \\
\text { How often do you have someone help you read hos- } \\
\text { pital materials? } \\
\text { How often do you have problems learning about } \\
\text { your medical condition because of difficulty read- } \\
\text { ing hospital materials? } \\
\text { All graded 1-5, scores range 3-15 (or 0-12 in } \\
\text { Cavanaugh et al. [13]) }\end{array}$ & $<1 \mathrm{~min}$ & $\begin{array}{l}\text { 3-8 (or 0-5): lower } \\
\text { 9-14 (or 6-12): moderate/higher } \\
(<10 / 15 \text { or }<6 / 12 \text { indicates limited health literacy) }\end{array}$ \\
\hline $\begin{array}{l}\text { Newest Vital Sign } \\
\text { (NVS) }\end{array}$ & $4(14)$ & $\begin{array}{l}\text { Six-item assessment of reading comprehension from } \\
\text { an ice-cream nutrition label }\end{array}$ & $\begin{array}{l}6 \mathrm{~min} \text { maxi- } \\
\text { mum (average } \\
2.9 \mathrm{~min}) \text { in } \\
\text { Weiss et al. } \\
{[14]}\end{array}$ & $\begin{array}{l}0-1 \text { : high likelihood marginal/inadequate } \\
\text { 2-3: possible marginal/inadequate } \\
\text { 4-6: adequate } \\
\text { (here, }<4 \text { deemed limited health literacy } \\
\text { in Devraj } \text { et al. }[15] \text { ) }\end{array}$ \\
\hline
\end{tabular}


Table 3. A mid-term care plan for a patient

\begin{tabular}{|l|l|}
\hline Patient ID & $* * * * * *$ \\
\hline $\begin{array}{l}\text { Initial training } \\
\text { period length }\end{array}$ & weeks \\
\hline $\begin{array}{l}\text { Home visit } \\
\text { frequency }\end{array}$ & $\begin{array}{l}\text { Every 2 weeks in first } 3 \text { months, then } \\
\text { every month }\end{array}$ \\
\hline $\begin{array}{l}\text { Home visit } \\
\text { length }\end{array}$ & 30 minutes \\
\hline $\begin{array}{l}\text { Home visit } \\
\text { preferred time } \\
\text { slot }\end{array}$ & After work time \\
\hline Priority & High \\
\hline $\begin{array}{l}\text { Possible } \\
\text { additional aid }\end{array}$ \\
\hline
\end{tabular}

Table 4. Task list

\begin{tabular}{|lr|l|l|l|}
\hline Task & $\begin{array}{l}\text { Time } \\
\text { window }\end{array}$ & $\begin{array}{l}\text { Skill level } \\
\text { required }\end{array}$ & $\begin{array}{l}\text { Preferred } \\
\text { slot }\end{array}$ \\
\hline $\begin{array}{l}\text { Task 1: } \\
\text { Patient ID; } \\
\text { Initial } \\
\text { training }\end{array}$ & $\begin{array}{l}\text { [Week1 1-day } \\
\text { 3] }\end{array}$ & Level 8 & Morning [M] \\
\hline $\begin{array}{l}\text { Task 2: } \\
\text { Patient ID; } \\
\text { regular visit }\end{array}$ & $\begin{array}{l}\text { [Week1 } \\
\text { day 1-day }\end{array}$ & Level 4-7 & $\begin{array}{l}\text { Afternoon } \\
\text { [A] }\end{array}$ \\
\hline $\begin{array}{l}\text { Task 3: } \\
\text { Patient ID; } \\
\text { efficiency } \\
\text { check visit }\end{array}$ & $\begin{array}{l}\text { day 1-day } \\
\text { 5] }\end{array}$ & Level 4-7 & Late day [L] \\
\hline $\begin{array}{l}\text { Task 4: } \\
\text { Patient ID; } \\
\text { sample } \\
\text { collection }\end{array}$ & $\begin{array}{l}\text { day 1-day } \\
\text { 2] }\end{array}$ & Level 4-7 & Morning [M] \\
\hline $\begin{array}{l}\text { Task 5: } \\
\text { Patient ID; } \\
\text { Initial } \\
\text { training }\end{array}$ & $\begin{array}{l}\text { [Week2 3-day } \\
\text { 5] }\end{array}$ & Level 8 & Morning [M] \\
\hline
\end{tabular}

\section{Carer's profile modelling}

PD is performed by patients (and/or carers) in the community. In most renal units the community dialysis teams provide training and support for renal patients at home. To provide patients comprehensive renal nursing care, a staff to patient ratio of up to $1: 20$ is recommended depending on geographical factors and travelling times. This would then enable a series of patient care activities, such as training of patients at home or in hospital, monthly nursing visits and support at home, quarterly nurse led multi-professional clinic visits, troubleshooting, management of anaemia, ongoing patient education, performance monitoring and audit. In Table 5, we give the skill levels of nurses for modelling purpose.
Table 5. Nurse skill level

\begin{tabular}{|l|l|}
\hline Level 8-10 & Senior registered practitioner \\
\hline Level 4-7 & Intermediate registered practitioner \\
\hline Level 4 & Newly registered nurse \\
\hline Level $0-4$ & Health care assistant \\
\hline
\end{tabular}

\section{Continuity of care modelling}

CKD patients need lifelong care involving medication, dialysis, and/or transplantation, etc. In long-term care, continuity of care is a highly sought attribute. Continuity of care develops a constraint in the proposed models. As a result the healthcare workforce has to be planned, scheduled and deployed with the consideration of continuity of care for patients.

We try to develop the right "chemistry" between patients and caring staff. It is intuitive to argue that patients do not like frequent changes of nursing staff. Therefore, continuity of care means that only one operator for each category is assigned to a patient. The principal operator, who is not changed for a long period, preferably provides all of the visits required by the patients to the operator's category.

\section{Problem formulation}

Our model is developed with patients' profiles which will be constructed from patient health literacy screen, care workforce profiles and patient-centred continue of care constraints which have been discussed in the above sections. The list of notation is given in Table 6 .

The patients' profiles will be developed based on patients' medical conditions, life styles, personal preferences and the results of health literacy screen which are illustrated by Table 1. Based on this, the PD team will make a visit plan for each patient as shown in Table 3. The key information in the visit plan for each patient consists of initial training period lengths, home visits frequencies, timeslots of home visits, expected length of home visits and any additional aids maybe needed. Then the visit list is constructed as shown in Table 4. Patients will be roughly clustered based on their home locations. To mathematically formulate the visit list based on patient profiles, we design the set of nurses denoted as $K$, and the set of visits at patients' homes denoted as $C$. For each visit $i \in C$ a time window is define as $\left[\alpha_{i}, \beta_{i}\right]$ as shown in Table 4 where $\alpha_{i} \geq$ 0 and $\beta_{i} \geq 0$ specify the earliest and latest respectively possible starting time of the visits. This time window need strictly meet the RAS guidelines we stated above, at the same time, allow certain flexibility with respect to individual patient's conditions and needs. We use parameter to model the skill category of carer. If $\lambda_{i}^{k}=1$, $\mathrm{k}$ has the skill to be assigned to visit $i$.

We use the parameter $\delta_{i}^{k}$ to model the continuity of care by assigning different values to the parameter. 
Parameter $\gamma_{i}$ is the priority of visit. The higher the parameter value, the more important the visit.

To model the problem, two sets of decision variables are defined: the binary scheduling variables $x_{i k d s}$ and the binary coverage variables $y_{i}$.

Table. 6 Notation in the modelling

\begin{tabular}{|c|l|}
\hline \multicolumn{2}{|l|}{ Sets: } \\
\hline$I$ & Set of task, index $i$ \\
\hline$K$ & Set of nurses/carers, index $k$ \\
\hline$D$ & Set of scheduling day, index $d$ \\
\hline$S$ & Set of slot, index $s$ \\
\hline \multicolumn{2}{|c|}{ Parameters: } \\
\hline$\gamma_{i}$ & The priority of task $i$ \\
\hline$\delta_{i}^{k}$ & The continuity of care parameter \\
\hline$C_{k}$ & The contacted working slot for nurse $k$ \\
\hline$\theta_{k}$ & Overtime slot for nurse $k$ \\
\hline$\lambda_{i}^{k}$ & Skill category parameter \\
\hline$\rho_{i}^{S}$ & Patient's preferred slot \\
\hline$\alpha_{i}$ & The earliest starting time for task $i$ \\
\hline$\beta_{i}$ & The latest starting time for task $i$ \\
\hline$w_{1}, w_{2}, w_{3}$ & Weightings of objective funtions \\
\hline
\end{tabular}

$\min w_{1} \sum_{i \in I} \gamma_{i} y_{i}+w_{2} \delta_{i}^{k} \sum_{d \in D} \sum_{s \in S} x_{i k d s}+w_{3} \sum_{k \in K} \theta_{k}$

s.t.

$\sum_{k} \sum_{d} \sum_{s} x_{i k d s}+y_{i}=1, \forall i \in I$

$\sum_{d} \sum_{s} x_{i k d s} \leq \lambda_{i}^{k}, \forall i \in I, k \in K$

$\sum_{k} \sum_{d} x_{i k d s} \leq \rho_{i}^{s}, \forall i \in I, s \in S$

$\alpha_{i} \leq \sum_{k} \sum_{s} x_{i k d s} \leq \beta_{i}, \forall i \in I, d \in D$

$\sum_{i} x_{i k d s} \leq 1, \forall k \in K, d \in D, s \in S$

$\sum_{i} \sum_{d} \sum_{s} x_{i k d s} \leq C_{k}+\theta_{k}, \forall k \in K$

$x_{i k d s} \in\{0,1\}, \forall i \in I, d \in D, k \in K, s \in S$

$y_{i} \in\{0,1\}, \forall i \in I$

The objective (1) is a multi-objective function, which consists of the visits covering priority (the first term), the continue of care (the second term) and the overtime cost (third term). The weight can be set accordingly to emphasis the importance of each object. Constraint (2) ensures that each visit is covered exactly once or left uncovered. Constraint (3) ensures that nurse can only perform the task that is in his/her skill set. Constraint (4) ensures that each task is scheduled in patients' preferred time slot. Constraint (5) models the flexible date in which a patient's visit can take place. Constraint (6) states that for each nurse can only perform one task on a particular day and particular slot. Constraint (7) states that for each nurse that the total working slots are within the contract hours of working slots plus overtimeworking slots. Constraints (8) and (9) define the decision variables.

The complexity of the model is embedded in the task set I. It links tasks, patients, nurses' skills and time slots together. This task list will be constructed based on PD care pathway, as well as patient's health literacy and personal preferences. At this stage we are undergoing the model validation by our clinic partner before we start to collect the data.

\section{CONCLUSIONS}

A rigorous model of $\mathrm{HHC}$ cooperating $\mathrm{BOR}$ for the renal patients taking $\mathrm{PD}$ at their own homes has been established. We are going to present this model to the PD team in a major renal unit in collaboration with us to validate the model. Based on the feedback we will gather the corresponding information to conduct a case study on the HHCNSP problem.

In general, solving this HHCNSP problem is computationally challenging. To tackle this complex problem efficiently, we will investigate hybrid solution methods in our future work. These hybrid methods integrate and take the advantage of different techniques from different disciplines such as Integer Programming, Constraint Programming and local search algorithms. The clinical results will be reported in our future publications.

\section{REFERENCES}

Blais, M., Lapierre, S. D., and Laporte, G. 2003. "Solving a home-care districting problem in an urban setting". Journal of Operational Research Society, 54(11), 1141-1147.

Burke, E. K., De Causmaecker, P., Vanden Berghe, G., and Van Landeghem, H. 2004. "The state of the art of nurse rostering". Journal of Scheduling, 7, 441-499.

Borsani, V., Matta, A., Beschi, G., and Sommaruga, F. 2006. "A home care scheduling model for human resources". In Proceedings of ICSSSM, Troyes, France: 449- 454.

Cheang, B., Li, H., Lim, A., and Rodrigues, B. 2003. "Nurse fostering problems - A bibliographic survey". European Journal of Operational Research, 151, 447-460.

Chouvarda, I.G., Goulisc, D.G., Lambrinoudakid,I., and Maglaverasa,N. 2015. "Connected health and integrated care: Toward new models for chronic disease management". Maturitas, 82, 22-27.

Carello, G., Lanzarone, E. 2014. “A cardinality-constrained robust model for the assignment problem in Home Care 
services ". European Journal of Operational Research 236: 748-762

Haggerty, J., Reid, R., Freeman, G., Starfield, B., Adair, C., and McKendry, R. 2003. "Continuity of care: A multidisciplinary review". British Medical Journal, 327, 1219-1221.

Ham, C., Dixon, A., and Brooke, B. 2012. Transforming the delivery of health and social care: the case for fundamental change. The King's Fund.

Hallsworth, M., Snijders, V., Burd, H., Prestt, J., Judah, G., Huf, S., and Halpern, D. 2016 "Applying behavioral insight: simple ways to improve health outcomes". Report of the WISH Behavioral Insights Forum.

Hertz, A., \& Lahrichi, N. 2009. "A patient assignment algorithm for home care services". Journal of Operational Research Society, 60(4), 481-495.

Lahrichi, N., Lapierre, S. D., Hertz, A., Talib, A., and Bouvier, L. 2006. "Analysis of a territorial approach to the delivery of nursing home care services based on historical data”. Journal of Medical Systems, 30(4), 283-291.

Lanzarone, E., Matta, A. 2014. "Robust nurse-to-patient assignment in home care services to minimize overtimes under continuity of care". Operations Research for Health Care (3): 48-58

Lanzarone, E., Matta, A., and Sahin, E. 2012. "Operations management applied to home care services: The problem of assigning human resources to patients". IEEE Transactions on Systems, Man and Cybernetics, Part A: Systems and Humans, 42(6), 1346-1363.

Pessôa, L.A.M., Lins, M.P.E., da Silva, A.C.M. and Fiszman, R. 2015. "Integrating soft and hard operational research to improve surgical centre management at a university hospital". European Journal of Operational Research, 245 (3): 851-861.

Shortell, S.M. 1976. "Continuity of medical care: conceptualization and measurement". Medical Care. 14(5): 377-391

Taylor, D.M., Fraser, S., Dudley, C., Oniscu, G.C., Tomson, C., Ravanan, R., and Roderick, P. 2017. "Health literacy and patient outcomes in chronic kidney disease: a systematic review ". Nephrol Dial Transplant: 1-14

\section{AUTHOR BIOGRAPHIES}

FANG HE was born in China and received her $\mathrm{PhD}$ degree in Computer Science from The University of Nottingham, UK. Currently she is a lecturer in the School of Computer Science and Engineering. Her research interests include Operational Research techniques (Integer Programming, Stochastic programming), Artificial Intelligence (Constraint Programming), Heuristics methods (meta-heuristic) and Applied Operational Research techniques for decision making, particularly in the application areas as scheduling and optimisation in healthcare sector and other service sectors.

THIERRY CHAUSSALET recieved a PhD degree from North Carolina State University (USA) in Probability and Stochastic Processes. He started his career in the UK as a lecturer in Decision Sciences. With a growing interest in modelling health and social care, he co-founded in 1998, with Professor Peter Millard, the Health and Social Care Modelling
Group at the University of Westminster, and became Professor of Healthcare Modelling in 2007. His research interests are quantitative modelling of management processes, intelligent data driven methods for informed decision making and performance management, and data science for resources planning and management.

RONG QU is an Associate Professor of Computer Science, at the School of Computer Science, The University of Nottingham, UK. Her research interests are on the modelling and optimisation algorithms (meta-heuristics, mathematical approaches and their hybridisations) to real-world optimisation and scheduling problems. 